Ralstonia solancearum انتاج عدة تثخيصية مناعية للكثف عن سلالتين للبكتيريا بطريقة اليزا ELISA (smith)

\title{
Production an immuno kit for identification two strains of Ralstonia solancearum (smith) by ELISA which caused a bacterial wilt on tomato in Iraq
}

مركز بحوث التقنيات الأحيائية / جامعة النهرين

Raed Raouf Al-Aniy

Biotechnology Research center/ Al-Nahrain University

تعتبر البكتيريا Ralstonia solanacearum أحد أهم المسببات المرضية التي تصيب الطماطة وتسبب

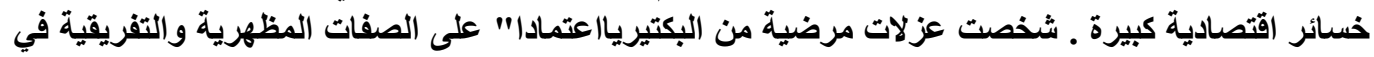
Tetrazolium chloride agar (TZS) هanthi من هذه البكتيريا هي R1 R3 و حصل على المصل المضاد لكل سلالة بعد حقن المعلق البكتيري النقي لكل

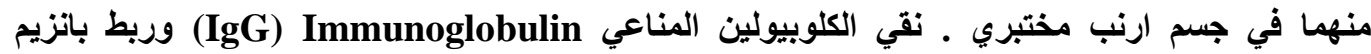
الفوسفاتيز القاعدي Alkaline phosphatase لأستخدامها كعدة تثخيصية لكل سلالة في اختبار اليزا

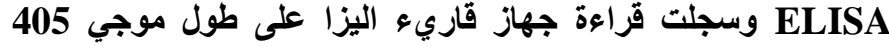

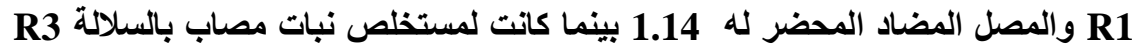

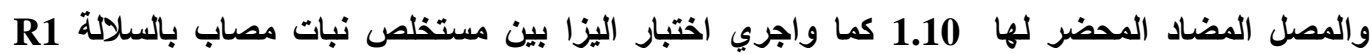

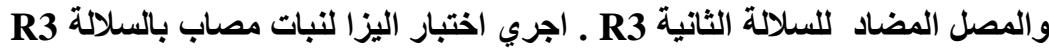

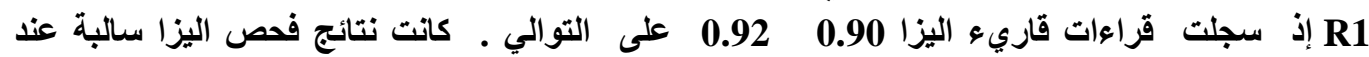

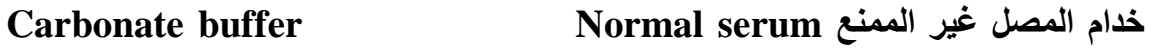
لليل واضح على التخصص العالي للمصل المضاد المنتج في هذه الدراسه .

Abstract

21 alstonia solancearum is one of most important tomato pathogen which L annually causes considerable yield loss. Strains of these pathogenic bacteria were identified based on both phenotypic and differentiation media on Tetrazolium Chloride Agar (TZC) and the hypersensitivity tests on leaves of tobacco cultivar xanthi. Many biochemical adapted tests were carried out for identification of both the genus and species of the bacteria. Two strains R1 and R3 were identified. Antiserum of each strain was obtained following the injection of pure cell suspension of each strain in lab. Rabbit. Immunoglobulin (IgG) was purified and conjugated with alkaline phosphates and used as an identification kit for each strain by ELISA test .The reading of ELISA reader at 405 nanometer when testing plant extract infected by $R 1$ strain with its antiserum were 1.14 while it was 1.10 for R3 strain, ELISA test were also carried out for plant extract infected by R1 strain and the antiserum of R3 strain, ELISA test were carried out too for plant infected by $R 3$ strain and antiserum of $R 1$ strain the reading of ELISA reader were $0.90,0.92$ respectively. The result of ELISA 
test was negative when using the normal serum and carbonate buffer as antiserum. The result of this test is clear evidence showed the high specify of the antiserum which produced in this study.

المقدمة

تعد الطماطة.Lycopersicn esculentum L من المحاصيل الغذائية العالية وهي من أهم محاصيل الخضر

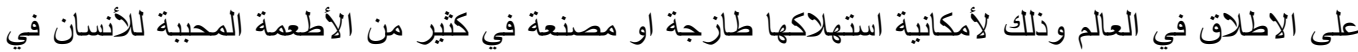

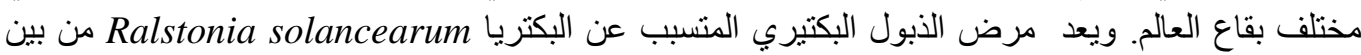

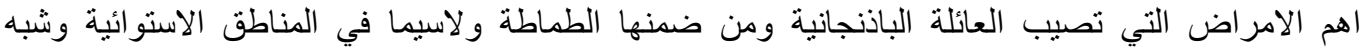

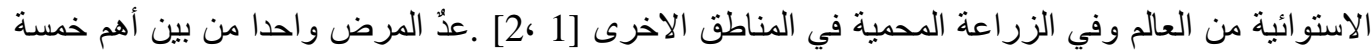

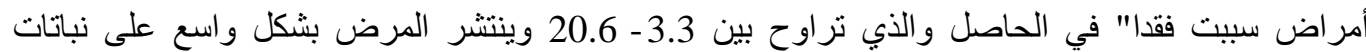

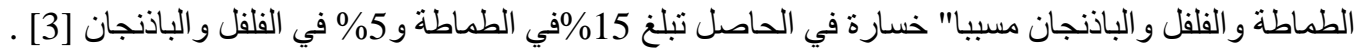

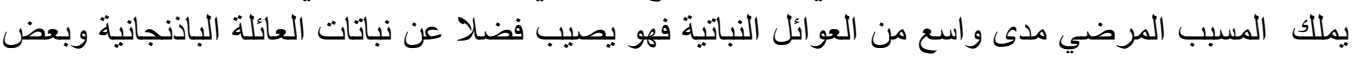

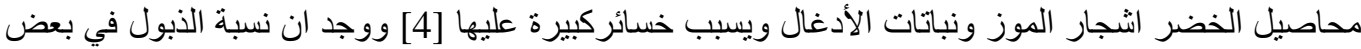

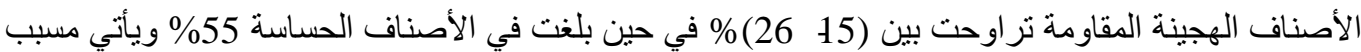

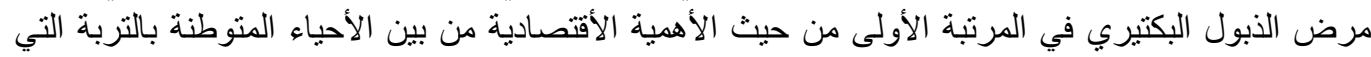

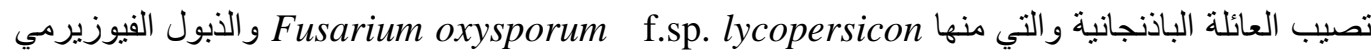
المتسبب عن الفطر F. oxysporum f.sp. lycopersici فضلا عن الأمر اض البكتيرية الأخرى التي تصيب الأني الطماطة [5] ـ أثنتت الدراسات التصنيفية ان للبكتيريا Ralstonia solanacearum عددا" من السلالات التي يمكن التمييز بينها في بعض الصفات الفسيولوجية وطبيعة رد فعل اوراق التبغ Hypersensitive Reaction

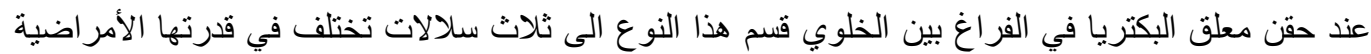

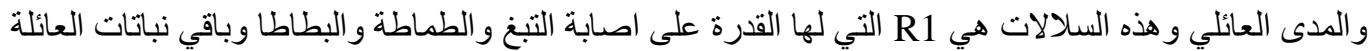

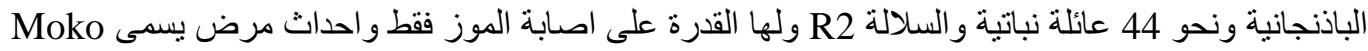

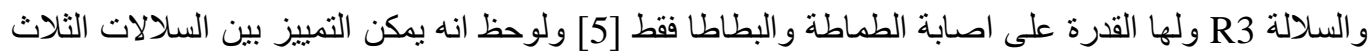

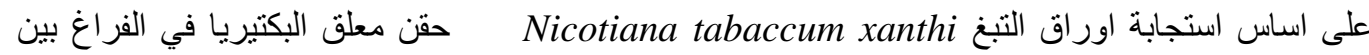

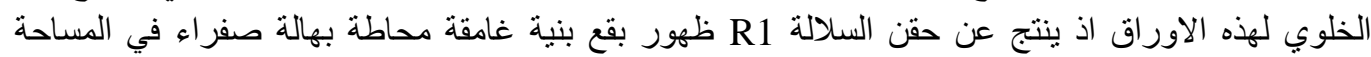

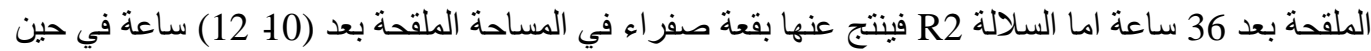
ان السلالة R3 ينتج عنها اصفرار للمساحة الملقحة من الورقة بعد 48 ساعة[4] ـ قسَمت البكتيريا الى اربعة

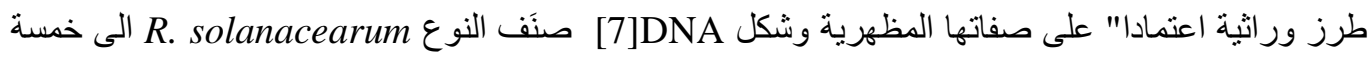

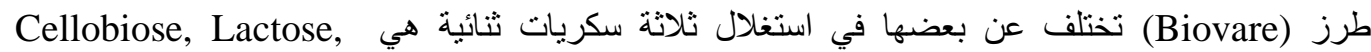

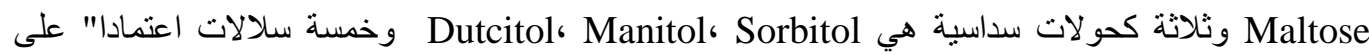
المدى العائلي لها ، فالسلالة الأولى تصيب نباتات العائلة الباذنجانية والعديد من النباتات العائدة لعوائل العائل مختلفة

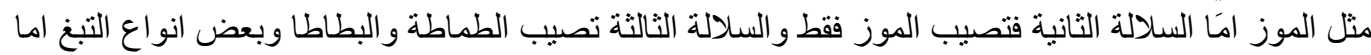

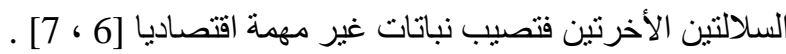

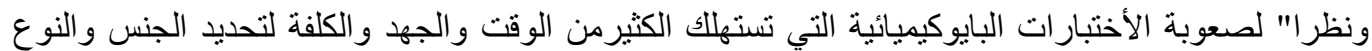

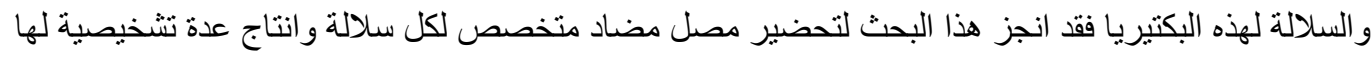

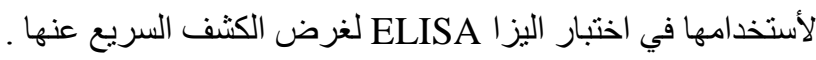

:

جمع العينات

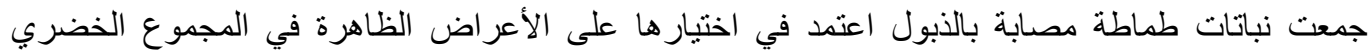

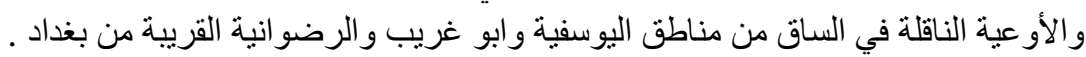

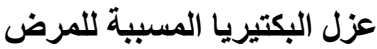

عزلت البكتيريا من النباتات المصابة حيث غسلت بالت بالماء الجاري لأز الة ما يعلق بها من نربة ، وقطعت سيقان

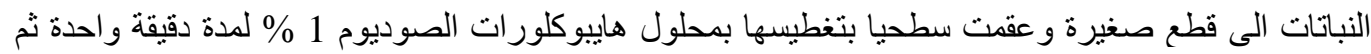


غسلت السيقان بما ء مقطر معقم وجفقت على ورق ترشيح ـ أخذت عدد من السيقان التي يظهر فيها تلون نسيج

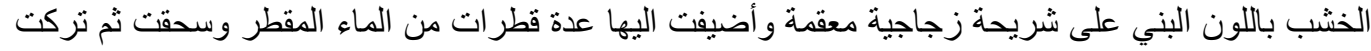

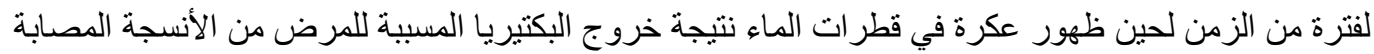

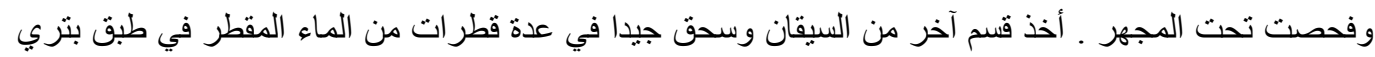

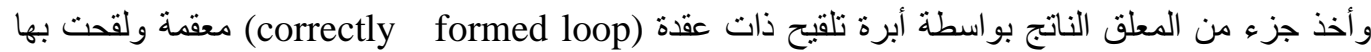

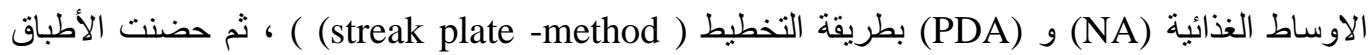

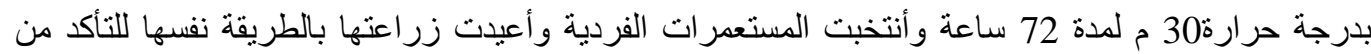

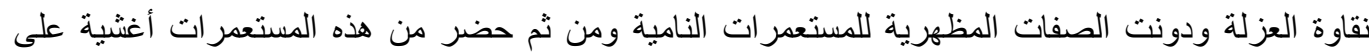

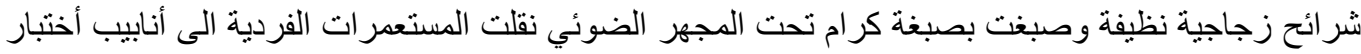

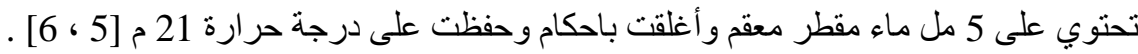

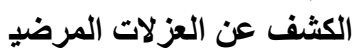

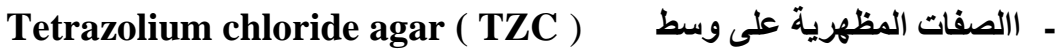

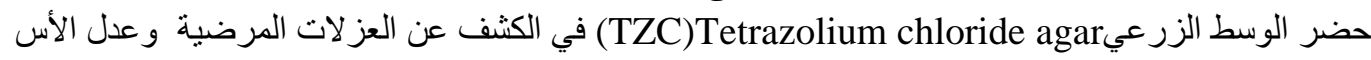

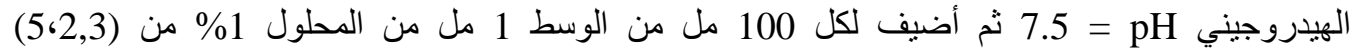
triphphenyl tetrazolium chloride

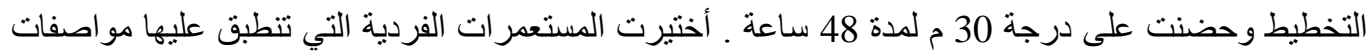

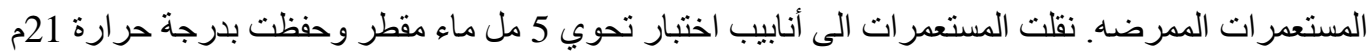

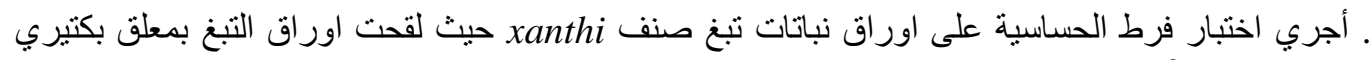

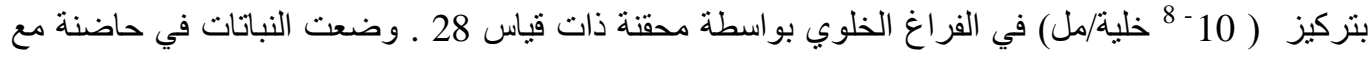

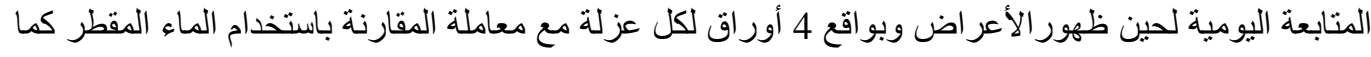

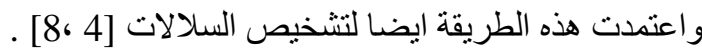
تثخيص الجنس

درست بعض الصفات المظهرية والمجهرية للعزلات المرضية المختارة فضلا عن بعض الصفات البايوكيميائية للوصول الى الجنس . Ralstonia SPP وكما يلي: الصفـات المظهريـة المئة طبيعة النمو في الأوساط الغظات المطائة

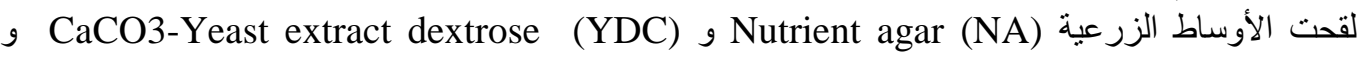
مutrient Broth (NB) Kings Medium(KB)

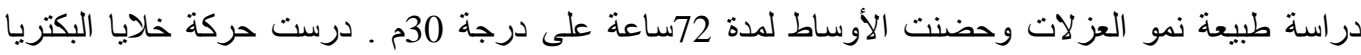

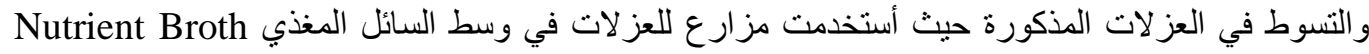

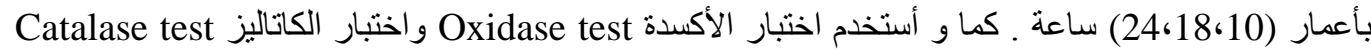

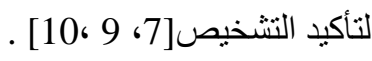

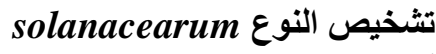
أجريت اختبار ات عديدة لنتخيص النوع solancearum شملت اختزال النتر ات Nitrate reduction وحسب وفحص الأندول Indol test وانتاج كبريتيدالهيدروجين Production of hydrogen sulfide انتاج الأمونبا من البيتون (Production ammonia from peptone)و التحلل المائي للآرجنين( Argenin

. [6] (dihydrolase عزل سلالات البكتريا

تم التمييز بين سلالات البكتريا وذللك بتحضير لقاح بكتيري تركيز 10 هُ مستعمرة/مل من كل عزلة بلة بكتيرية نامية

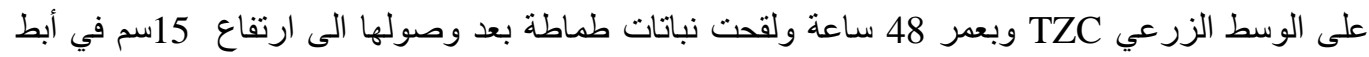

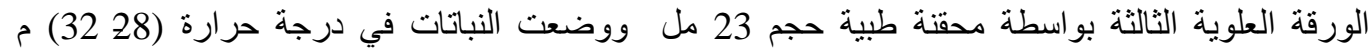

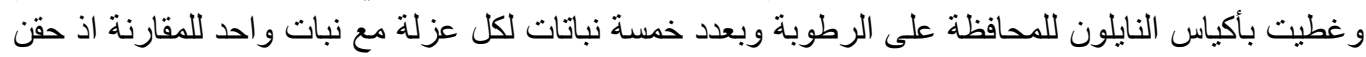

بالماء المقطر [7] . 
تحضير مصل مضاد متخصص لسلالات البكتيريا :

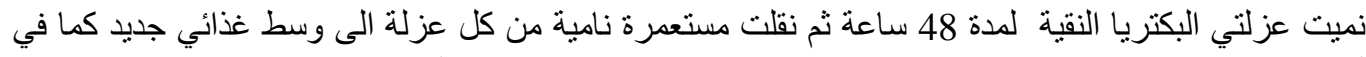

أعلاه وحضر مصل مضاد للعزلتين البكتيرية باتباع طريقة

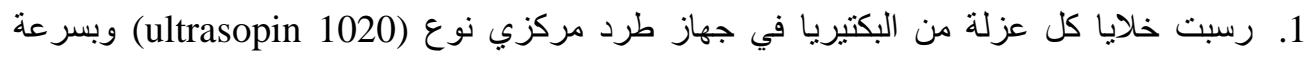

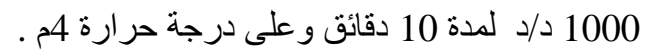

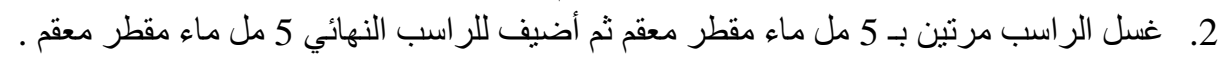

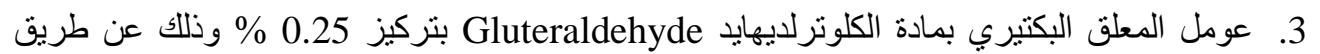

الأنتشار الغشائي (Dialysis) لمدة اليكيري 12 ساعة.

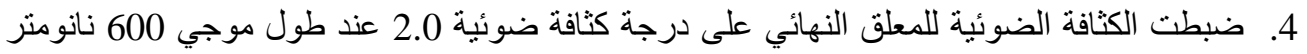

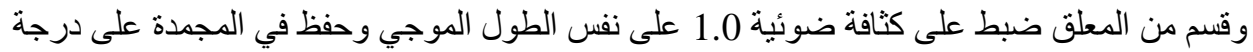

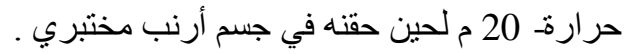

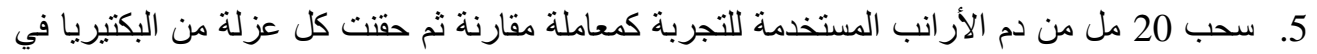

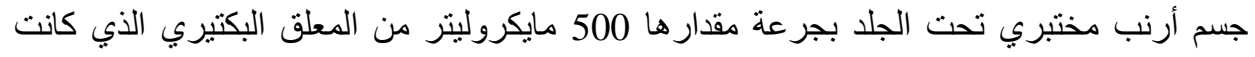

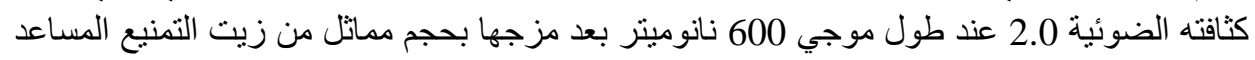

. Freund's incomplete adjuvant

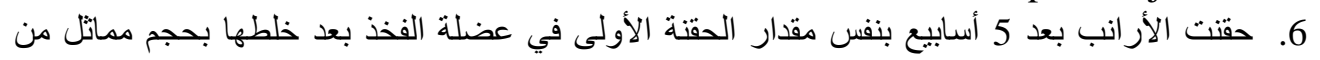

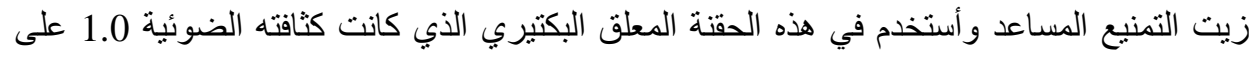

طول موجي 600 نانومتر.

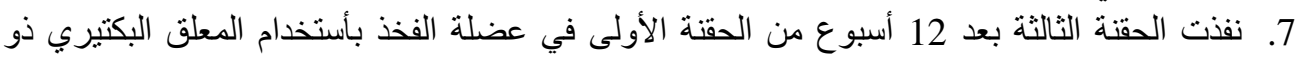

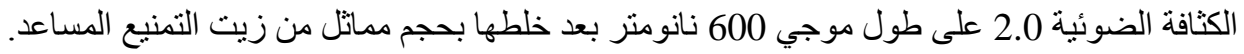

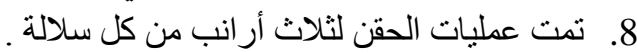

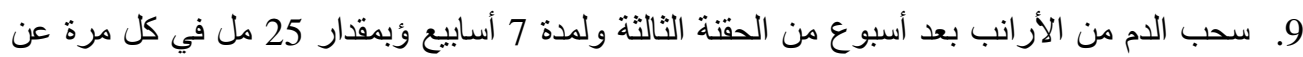

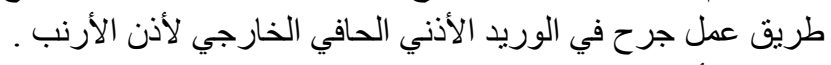

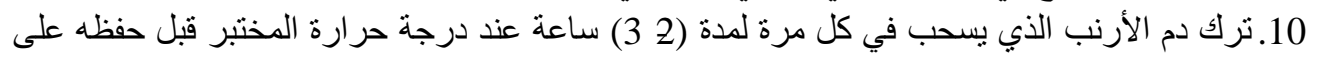

$$
\text { م4 ئوي لمدة (10 12 12) ساعه. }
$$

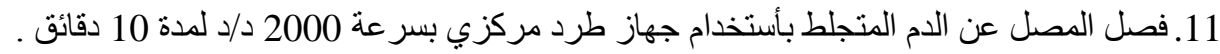

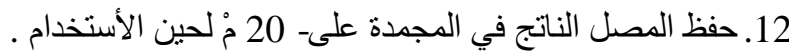

ربط الأجســـــــــام المضادة بالأنزيم :

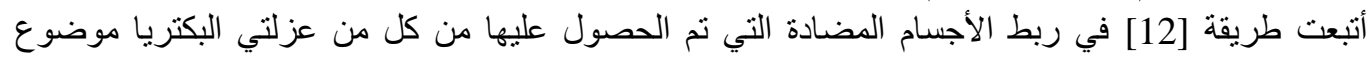

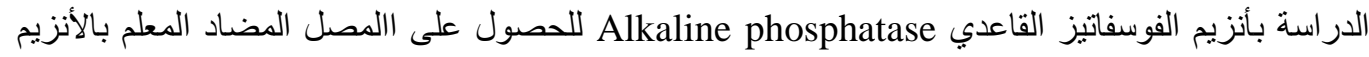
وكالتالي :

Immuonoglobulin Gama (IgG تنقية الكاماكلوبيولين :

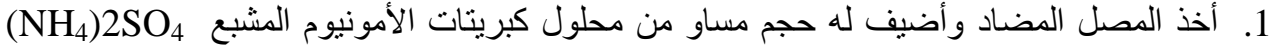

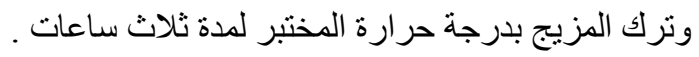

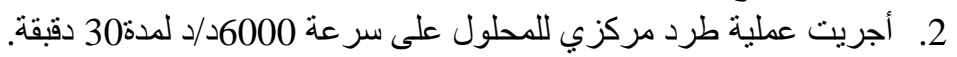

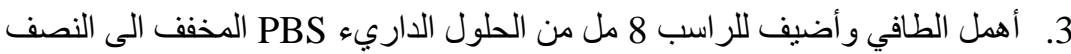

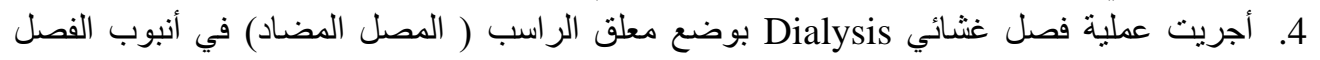

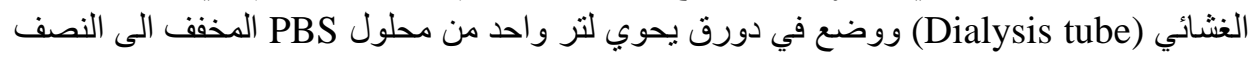

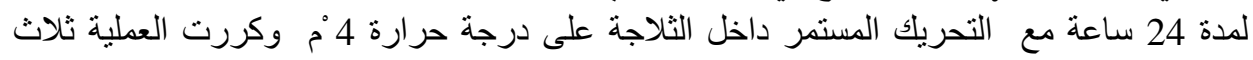
مرات. - مات.

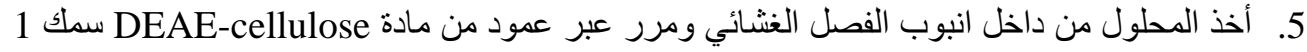
سم في ماصة زجاجية وضعت قطعة من الصوف الزجاجي في قاعدة ماصة زلئ زجاجية ذات حجم 5 مل 
مثبتة على حامل ووصلت نهايته السفلى بانبوب مطاطي مثبت عليه كلاب حديدي لغرض التحكم بعملية الفتح و الغلق بسهولة.

6. وضع 2 مل من المصل فوق طبقة السلبلوز وجمع المصل من أسفل الماصة وبذا نم الحصول على

.IgG

: بط الأجسام المضادة بالأنزيم :

أخذ 1 مل من مستحضر الكاماكلوبيولين IgG بتركيز 1 ملغم/مل وأضيف الئه 2 ملغنغ من انزيم الفيم الفوسفاتيز

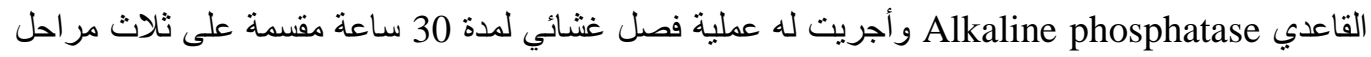

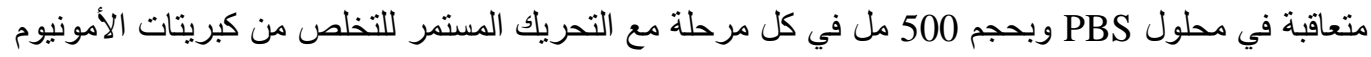

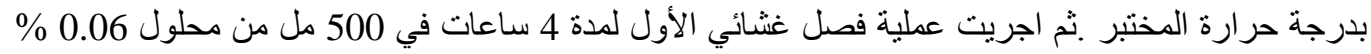

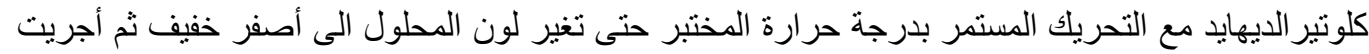

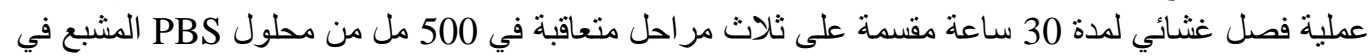

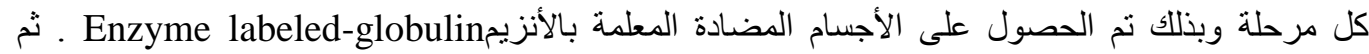

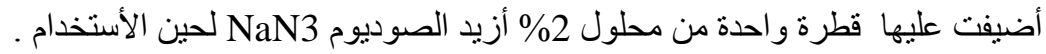

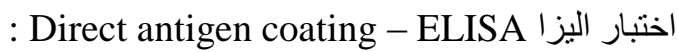

أتبعت طريقة Koenig [11] وذلك باستخدام معلق بكتبري محضر في محلول داريء الكاربونات 2.0arbonate buffer

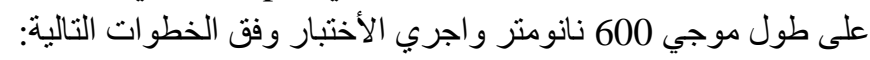

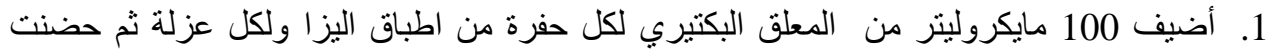

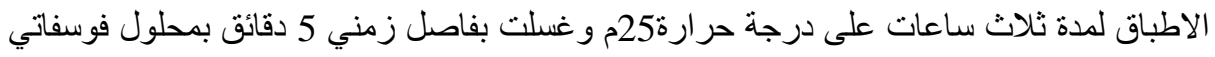
(Phosphate buffer saline- 7.4=pH يحتوي مادة 20 Tween ذو اس هيدروجيني

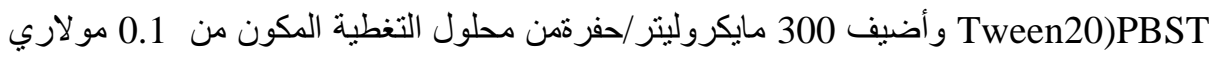

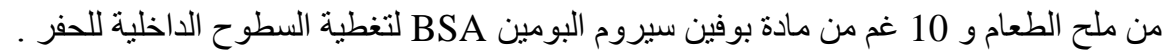

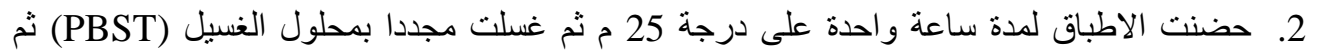

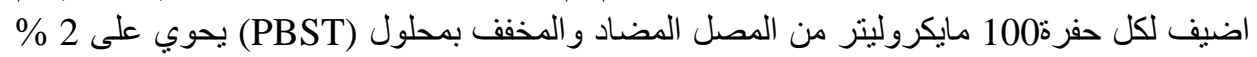

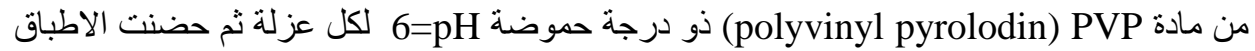

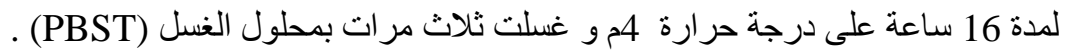

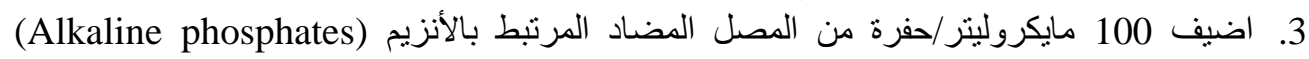

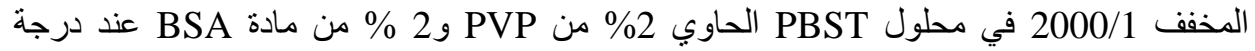

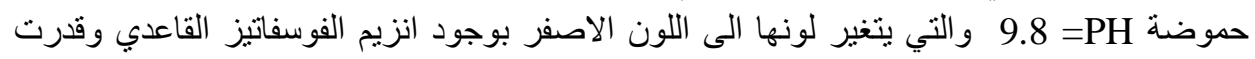

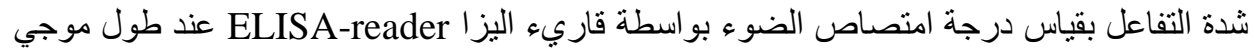
405 نانوميتر بعد 30 دقبقة . كما أستخدم اختبار اليزا لتحديد أفضل السحبات من الدم التي يمكن اعتمادها في عمليات الكثف عن عزلتي البكتيريا . 800/1، 400/ 1 ، 200/ 1 أجري كذلك اختبار اليزا من كل مصل عزلة الكن بكتيريا مع السلالة البكتيرية الأخرى لمعرفة مدى تخصص المصل

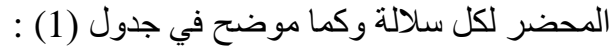
(1): اختبار اليزا لعزلة بكتريا والمصل المضاد المحضر لها وبين المصل المضاد المنتج لعزلة بكتريا وعزلة البكتريا الأخرى المصل المحضرلعزلة البكتريا

$\begin{array}{ll}\text { R1 } & \text { R3 } \\ \text { R3 } & \text { R1 } \\ \text { R3 } & \text { R3 } \\ \text { R1 } & \text { R1 }\end{array}$




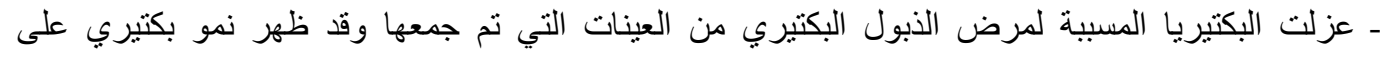
الوسطين الزرعيين NA، PDA بعد 24 ساعة من التحضين على درجة 30 م في حين لم تظهر المستعمر ات اتلئي

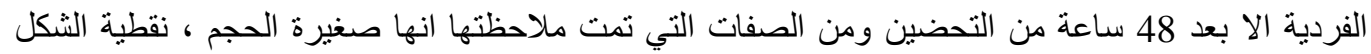

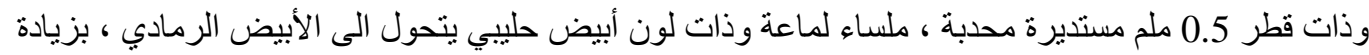

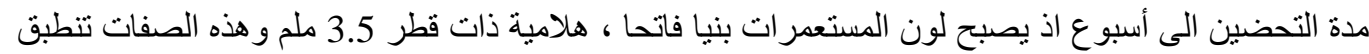

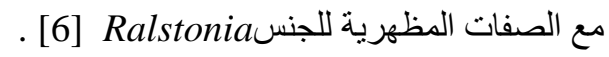
2.

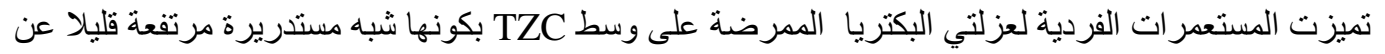

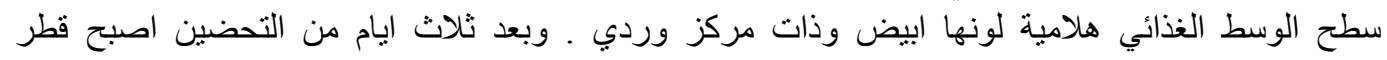

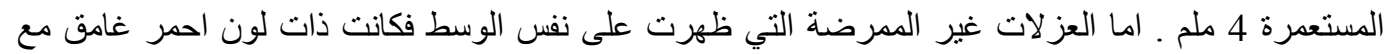

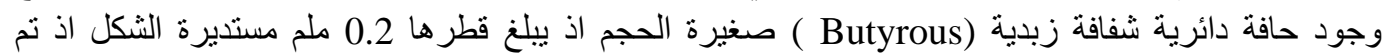

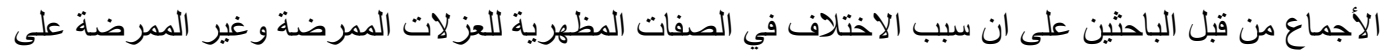

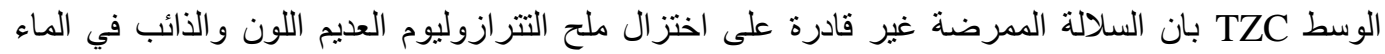

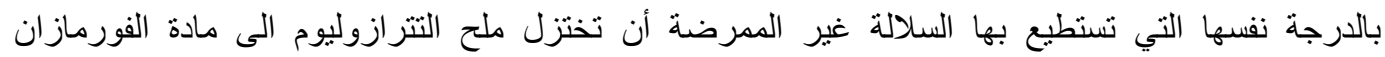

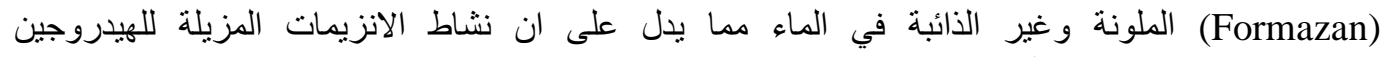
(dehydrogenase)

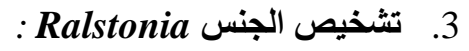

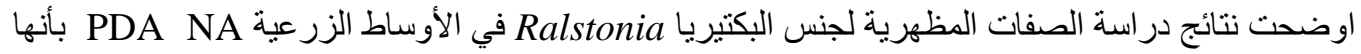

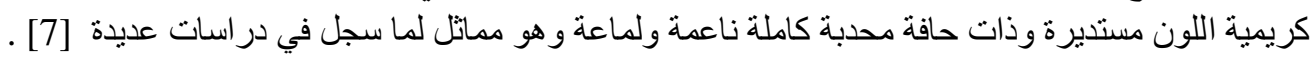
4. النمو في بعض الأوساط الزرعية

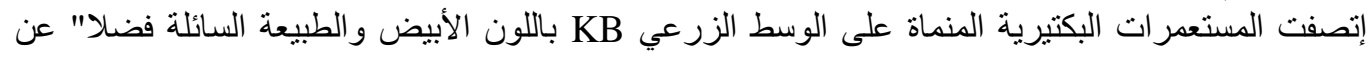

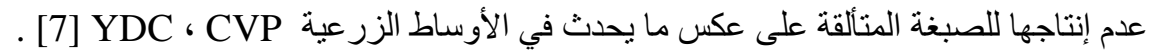

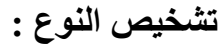

دراسة الصفات البايوكيميائية

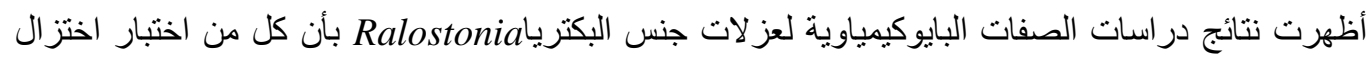

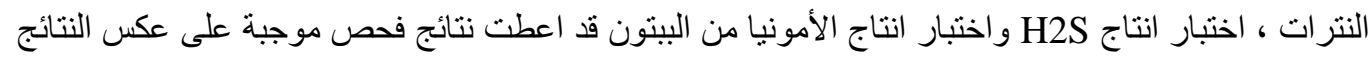

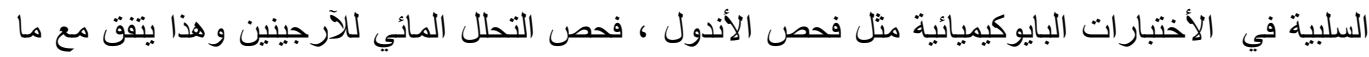

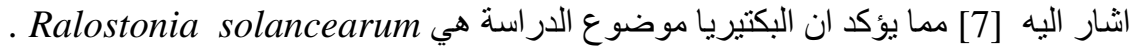
تشخيص السلانـة البه

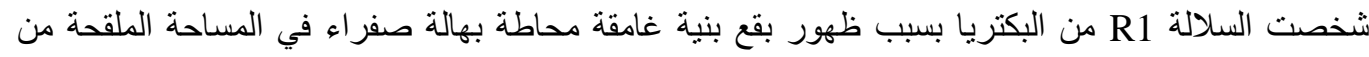

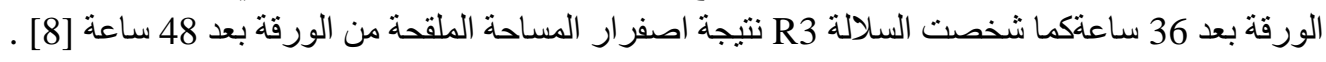

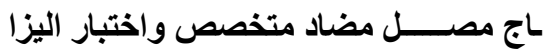

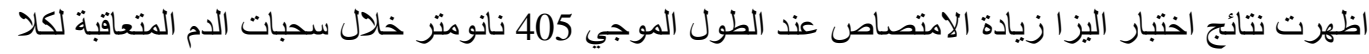

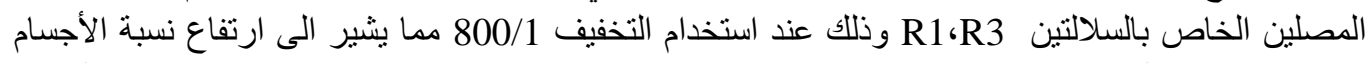

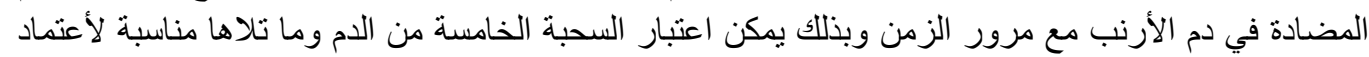

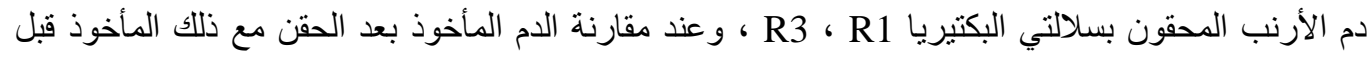

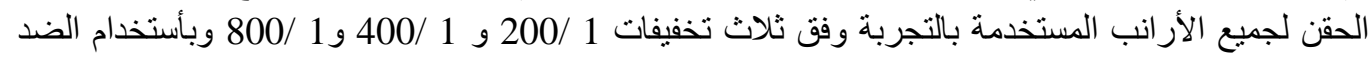

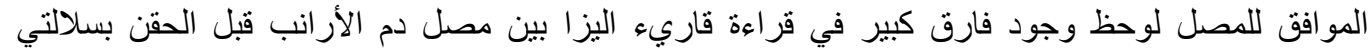

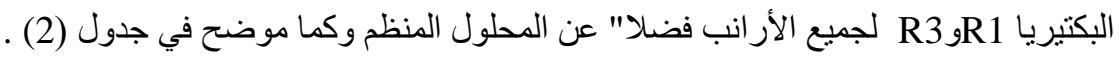


(2): قيم امتصاص قاريء اليزا على طول موجي 405 نانومترلعزلتي البكتيريا R3 R1 R. solancearum عند فحصها

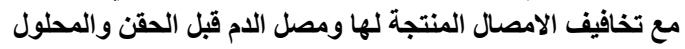

أمصالها

قراءات قارى اليزا

التخافيف

عزلة البكتريا

1.65

1.43

0.38

0.34

200/1

1.40

1.63

1.40

1.38

0.53

0.32

$400 / 1$

0.49

0.31

$800 / 1$

0.39

0.33

$200 / 1$

0.51

0.36

$400 / 1$

$\begin{array}{lll}0.47 & 0.38 & 800 / 1\end{array}$

$\begin{array}{lll}0.47 & 0.38 & 800 / 1\end{array}$

R1

R3

R. solancearum

(3) مقار الأمتصاص في جهاز قاريء اليزا عند استخام مصل مضاد من البكتيريا الأخرى للبكتريا على طول موجي 405

عزلة البكتيريا

\section{Optical density}

1.95

0.90

R1

0.90

R1

R3

1.94

R3

$\mathrm{R} 1$

R3

R3

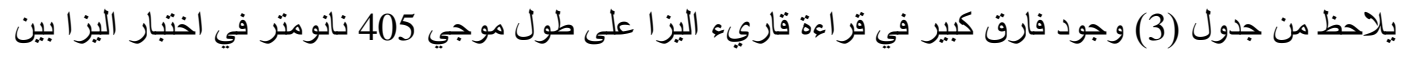

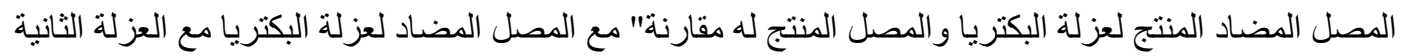

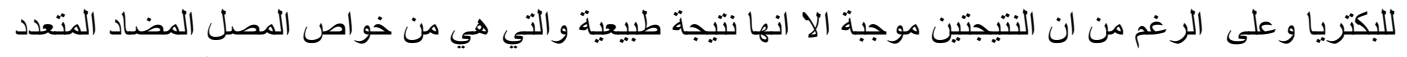

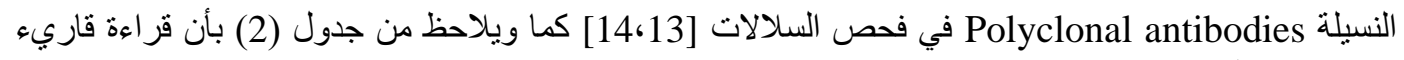

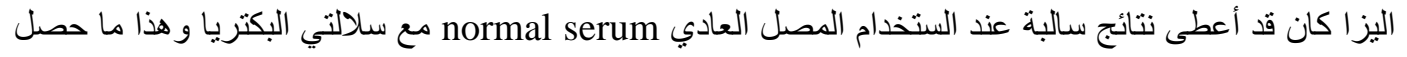

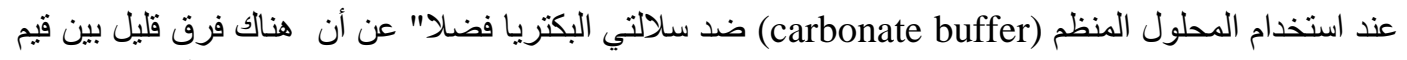

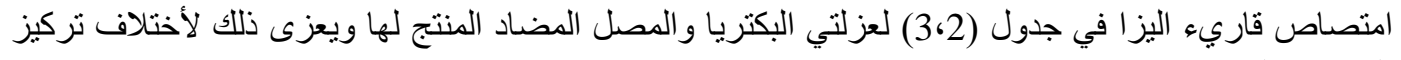

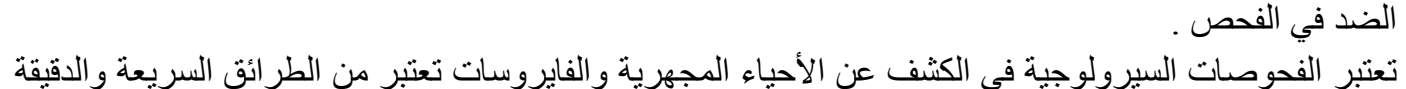

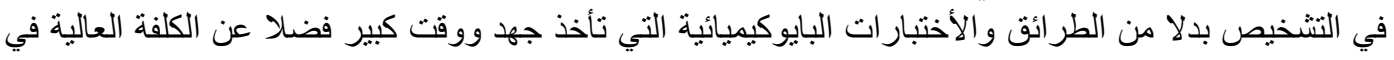

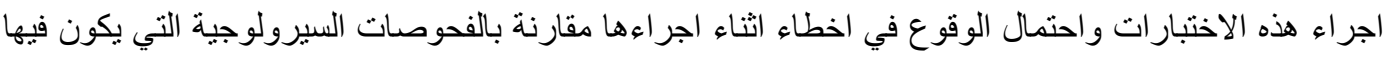

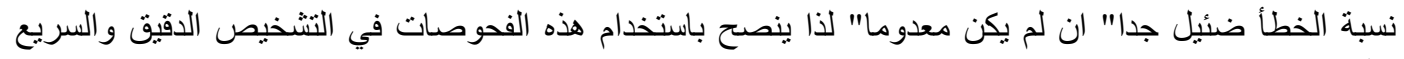

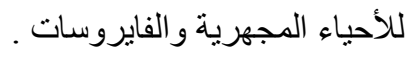

1. Shamb, P.Dhital. N.Thaveechai and Sundar, K.Shresta .2001.Characteristics of Ralstonia solansearum strains of potato wilt disease from Nepal and Thailand. Nepal Agric. Res. J. Vol. 5 2000/2001.

2. Wang, J.F.: Hanson. And Barnes, J.A.1998. Worldwide evaluation of an international set of resistance source to bacterial wilt in tomato. Pages 269-275 in: Bacterial Wilt Disease: Molecular and Ecological Aspect. Prior P.: Allen, and Elphinstone, J.eds .Spring -Verlag, Berlin, Germany.

3. Hayward, A.C.1991.Biology and epidemiology of bacterial wilt caused by Pseudomonas solancearum. Annual Review of Phytopathology 29:65-87. 
4. S.A.Weller,; J.G.Elphinstone ; N.C.Smith ; N.Boonham and D.E.Stead .2000.Detection of Ralstonia solansearum Strains with a quantitative ,Multiplex ,Real-Time, Fluorogenic PCR (TaqMan) Assay .Applied and Environmental Microbiology 66:2853-2858.

5. Norman David ,J.; Zapata Mildred.; Gabriel Dean W.; Duany,P.; Yuen Jeanne ,M.F.;Donahoo Ryan,S. 2009. Genetic Diversity and Host Range of Ralstonia solancearum strains Entering North America. Americanphyto Pathological Society, St.Paul, NN, ETATS-UNIS (1911) (Revue)

6. Ymada,T.,Kawasaki,T.,Nagata,S.,Fujiwara,A.,Usami,S.,Fujie,M.2007.New acterial phytopathogen Ralstonia solanceam.Microbiology 153:2630-2639.

7. Emmanuel Wicker.;Laurence Grassart.;Regin Corason-Beaudu.;Daniele Mian ;Caroline Guilbaud.; Mark Fegan and Philippe Prior.2007.Ralstonia solancearum Strains from Martinque (French West Indies) Exhibiting a New Pathogenic Potential. American Society for Microbiology 73:6790-6801.

8. Kiraly , Z.and Klement ,Z. 1974.Methods in Plant Pathology with Special Reference to Breeding for Disease Resistance to Breeding for Disease Resistance .Academic Press, New York.

9. McDonald and Mehan,V. K.1995. Technique for resistance screening against ground nut bacterial wilt. Teqnique Manual.No.1 (ICARDA).

10. Crabtree, K.T.and Hinsdill, R.D.1974. Fundamental experiments in microbiology .Saunders, W.B.Comp.

11. Koeing , R.1981.Indirect ELISA methods for the broad specifity detection of plant viruses. Journal of General Virology 55:475-483.

12. Clark, M. and A. Adam .1977.Characteristics of the microplate of Enzyme Linked Immunosorbent Assay for detection of potato viruses'. Virology.34:475-483.

13. Mitsuo Horita ,and Kenchi Tsuchiya. 2000. Phenotypic and Cluster Analysis of Japanese Refrence Strains of Ralstonia solancearum .Ann.Phytopathol .Soc. Jpn. 65:604-611.

14. M.Machmud and Yadi Suryadi .2008.Detection and Identification of Ralstonia solancearum Using the Indirect ELISA Teqnique.Indonesian Journal of Agriculture 1(1):13-21 